\title{
Pedagogical pattern of running a course on secondary school students' achievement in waves
}

\author{
Nkwo Inyang Nkwo ${ }^{1}$, Margaret Ndidiamaka Anugwo ${ }^{2}$, J. O. Ugama ${ }^{3}$ \\ ${ }^{1}$ Department of Curriculum and Instructional Technology, Cross River University of Technology, Calabar, Nigeria \\ ${ }^{2,3}$ Department of Science Education, Ebonyi State University, Abakaliki, Nigeria
}

\section{Article Info \\ Article history: \\ Received May 10, 2020 \\ Revised Dec 23, 2020 \\ Accepted Jan 24, 2021 \\ Keywords: \\ Gender and achievement Pedagogical pattern \\ Running a course \\ Talk and chalk method}

\begin{abstract}
This study investigated the comparative effectiveness of pedagogical pattern of running a course and talk-chalk methods on senior secondary school students' achievement in waves. It is triggered by reports of persistent students' low achievement in physics contributed largely by students' poor performance in waves-related items. It adopted the quasi-experimental pretest-posttest control group design. Three research questions and hypotheses guided the study. There were 216 students who participated in the study. Physics Achievement Test (PAT) containing 50 multiple-choice researcher-developed items were used as instrument for data collection. Mean and standard deviation were used to answer the research questions while ANCOVA was used to test the hypotheses at 0.05 level of significance. Results showed that: the pedagogical pattern of running a course method was superior method in fostering students' achievement in waves; female students achieved higher than male students using pedagogical pattern of running a course strategy to teach waves; and there was no significant interaction effect of teaching methods and gender on students' achievement in waves. From the findings, it was recommended that the pedagogical pattern of running a course strategy should be used in teaching physics in secondary school education system and in training of teachers.
\end{abstract}

This is an open access article under the CC BY-SA license.

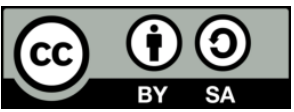

Corresponding Author:

Margaret Ndidiamaka Anugwo

Department of Science Education

Ebonyi State University

Abakaliki, Ebonyi State, Nigeria

Email: megito218@gmail.com

\section{INTRODUCTION}

The challenge still facing senior secondary school physics students is vexing, not only to physics and science educators in Nigeria but to other educators world-wide. This challenge may arise because physics as a basic science with profound influences on individuals, societies, institutions and the physical environments is grossly underutilized. The underlying influence is hinged on the fact that any persons who plan a career in science and its fringe disciplines should acquire fundamental ideas, concepts and principles of physics. This presupposes the primary purpose behind the secondary school physics teaching curriculum. The purpose is founded on giving to students the unified view of physics in line with their predisposition to the fundamental unity of science already existing in their prior behavior which they bring to a physics classroom.

Despite the indispensability of physics to life and living, students' mass failure in physics for the past four decades in Nigeria has often been described as unimpressive [1]. This is the state of physics in most countries of the world. This unimpressive situation is further remarked that, the teaching and learning of 
physics have been fraught with challenges which prevent many students from performing well in external examinations [2]. Therefore, these problems of abysmal students' low achievement in senior secondary schools have become an utmost issue of concern. The concern is necessitated by evidence-based research report of persistent students' low achievement in physics contributed largely by their poor performance in waves-related items of public examinations. One cardinal way of addressing the concern is directing focus on how to teach what to teach [3], intensifying efforts to ensure that this focus is suspected to be found in engaging active technique by the use of experiments and real-world problem-solving approach in context [4].

An active technique is an effective method in which a student is interactively engaged in teachinglearning activities for the purpose of constructing knowledge, possessing desired skills and disposition in order to manifest meaningful learning [5]. Meaningful learning is defined as learning with associated understanding [6]. One theme which content areas have posed difficulties to students' learning of physics is waves. Waves is defined as a physical phenomenon associated with disturbance of a medium that results in net energy transfer between any two points without material transfer of the medium particles. It has been recognized as third out of the six themes in Nigeria's senior secondary school physics curriculum. Waves are consequence of interaction of field concepts and broadly encompass optics, acoustics and electromagnetism. The five content areas of waves considered for the study include classification of waves, longitudinal waves, transverse waves, standing waves and progressive waves equations.

A look at the Chief Examiners' Reports on physics paper 2 of the West African Senior School Certificate Examination (WASSCE) for four years of May/June (2011-2014) West African Examinations Council WAEC [7] indicates strengths and weaknesses of the students with suggested remedial measures relative to students' achievement in waves items of the said examinations. The reports showed that students manifested: 1) Poor mastery in the manipulation of computational skills and arithmetic processes; 2) Inability to convert physical units correctly; 3) Inadequate grasp of many concepts; 4) Inability to relate acquired acknowledge to real-life situations; 5) Poor and incomplete rendering of laws and definitions; 6) Failure to recognize that diagrams are as important as explanations; 7) Language barrier problem which translates into poor language coordination, for which the students were neither able to understand the demands of some questions nor able to express themselves clearly.

These weaknesses as exuded on waves items largely, could be suspected to have led to students' low achievement in the physics examinations. The examiners commended the students for exuding strengths in items of other content areas of matter, space and time, conservation principles, fields, energy quantization and duality of matter, and physics in technology.

Against this backdrop, it is observed that teachers and students seem to be caught in the web of low cognitive processing abilities of waves concepts [8,9] because of its assumed theoretical, complex and abstract nature which evoke difficulty. This low ability has persistently led to mass failure in learning and low achievement [1]. Researchers [10-14] respectively, have linked this low achievement in waves to teachers' use of poor and inappropriate teaching methods holding that there should be a paradigm shift from the conventional ways physics is being taught, to more creative and innovative approaches. Converse to active technique, the talk and chalk traditional method of teaching is inalienably associated with piecemeal approach to instruction delivery. Thus, the learners are disarmed of properly equipped and relevant knowledge, and of the key disposition, values and skills that motivate and empower them to become informed citizens driven towards creating a better world for this and future generation [15]. A close look reveals that physics teachers still hold onto the teaching of physics as inert factoids that are given, received and absolute, alienated from the learning environment and devoid of the interactive engagement of the learners. In ensuring this interactive engagement.

Recent studies [16] maintain that the teacher and students should be given ample opportunities to adopt, adapt, develop, test experiment, analyze, practice, explore, make conjectures, hypothesize, examine, refute, devise plans, reason, conclude, justify conclusion, redesign and share design, reflect, monitor and experience. This is to bring about a creative-friendly learning environment and processes that physics has gone through [17] definitive component of teaching at the stimulation, guidance, direction and encouragement by the teacher. These exploits simulate the complexity of students' life in a typical physics classroom that creates contexts in which learning can happen in terms of acceptance of responsibilities and decision-making. In creating these contexts, the active technique found in pedagogical pattern of running a course stands out very uniquely when compared to the conventional method of talk and chalk due to analysis of conversation billed in the former [18]. From research reports on these disarming actions, physics teachers teach consciously by depending on chalkboard drawing and cardboard sketching without relating their lessons to what obtains in the learning environment [19].

This dependence depicts stereotypical stance evident in the received presentation of waves concepts as against the innovative notion of consensual knowledge construction and meaning-making based on the fact that both teaching and learning are a conversation according to Pask's analysis [20]. Therefore, the trend of 
persistent and continuous low achievement of students, in which research evidences have implicated teaching strategy as a major factor inhibiting students' achievement in physics, an alternative instructional intervention is viewed [21, 22] based on investigating the effects of pedagogical pattern of running a course on secondary school student's achievement in waves. The study is essentially a comparative effectiveness of this pedagogical pattern of running a course with talk and chalk method most popularly used in secondary school physics teaching, with attendant students' mass promotion, mass failure and continually declining achievement as years come by [23].

Pedagogy is an instructional as well as systematized learning approach that applies the practice, principle and theory of education to teaching. Pattern in the context of this study is a well-proven problemsolution pair presented in a structured format [24]. Pedagogical pattern is defined as a teaching-learning activity sequence designed to lead to specific learning outcome [25]. Researchers observe that students' mass failure in physics public examinations may be attributed to loss of focus on teaching. This loss of focus is observably located in mass promotion in schools, which denotes that little attention has been paid to effective technique in didactical and dialectical issues for educating people. A study [26] enunciates that didactical issues are based on systematic instruction or learning by instruction for which talk and chalk is located for transmission of knowledge to passive learners, while dialectical issues are based on systematic reasoning or learning by discovery and inquiry for which pedagogical pattern of running a course is located with emphasis on acquisition of knowledge, skills and attitudes by active learners.

From these relational issues, Eckstein [10] innovates the pedagogical pattern of running a course with a significant feature of "creating a context in which learning can happen." It is a family pattern of five interrelated, interdependent and completion patterns. This is because the next pattern follows from the previous one largely in a non-linear sequence as shown in the arrows linking one to another in a web presented in Figure 1.

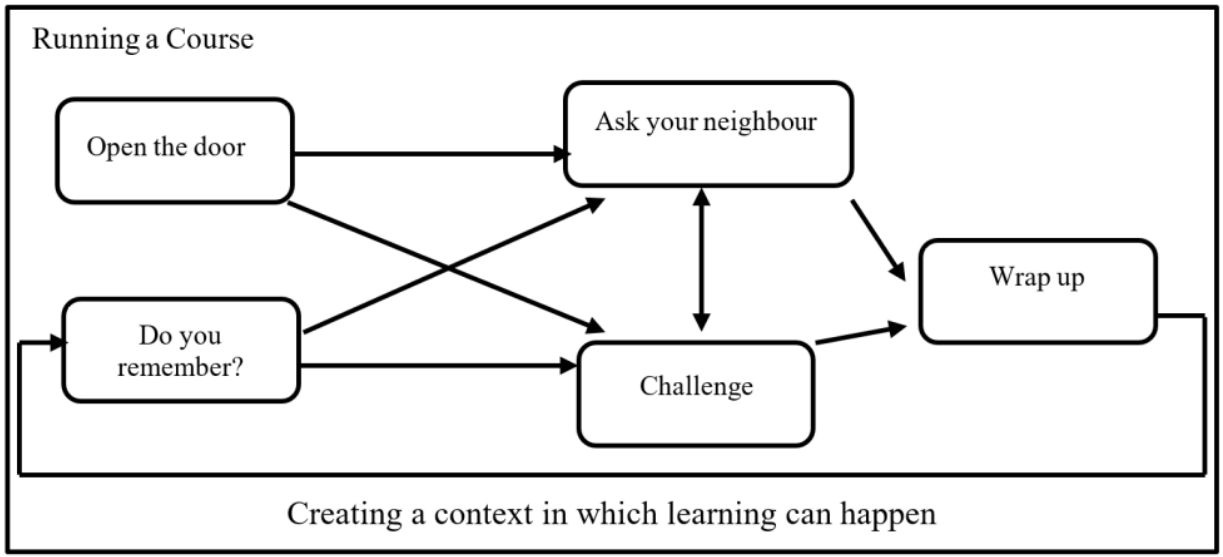

Figure 1. Pedagogical pattern of running a course [10]

Running a course is a pedagogical pattern culled from a pattern language titled "learning to teach and learning to learn." The five related patterns of running a course are: 'Open the door', 'Ask your neighbor', 'Challenge', 'Wrap up' and 'Do you remember?'

Briefly, the first one "open the door" addresses the issues of introducing or beginning or starting a lesson; teacher encourages students to ask each other about their knowledge of possible factors of classifying waves. Here, partner interview is used as an opener. Partner interview is an element of "open the door" in which students are allowed to interview each other at the beginning of a lesson while the teacher clarifies which questions, he or she will like them to answer, and watches the time used as students tend to talk forever. It is a perfect opening for physics as a subject related to distributed objects; it shows how every object could be server-object at one point and client-object at another point. A server object is used to initiate and access properties and method in a server while client object is a relationship between a component and a client's product. This is exemplified in a question posed by a physics teacher to a student on mentioning factors of classifying type of waves. The student after making attempt, passes the question to another student for help.

The second one, "Ask your neighbor" addresses the issues of giving opportunity for students to interact with themselves about a topic, lesson or concept introduced by the teacher; students are encouraged 
and given opportunity to think, ask and interact with each other and with the environment about possible factors that could be considered for classifying types of waves. Teacher draws students' attention to moving leaves and branches of tree-limb due to a blowing wind around the neighborhood of the classroom, and imagined movement of an object in a river tossed by waves. The elements of the pattern applied include group discussion, coaching and learner back-up. Group discussion here means a conversation arising from a lesson presentation before the group or whole class on the basis of student-student interaction as moderated by the physics teachers. Here, a teacher serves as both a facilitator and a participant. Examples and drawbacks are used to buttress issues of concern as the students attempt to find out from one another the possible factors of classifying types of waves. Coaching or scaffolding in this context is a teaching technique of using a brighter student or fast learner to lead weak ones towards learning a task of mentioning and classifying factors of waves types. Learner back-up is also a technique in which a learner relies on another learner for contributions towards mentioning factors of classifying types of waves in the absence of a teacher.

The third one "challenge" provides opportunity for students to bring out solution to the problem posed instead of depending on the teacher as the only one to trust. The pattern is premised on the fact that a mix of students can provide automatic solution, because there may not be only one solution but often many equally possible correct answers from many groups of students as may be formed. Teacher encourages students in their groups to initiate their own solutions through co-operation or collaboration in order to find out possible factors of classifying waves into its types. Teacher may provide hints, structures, clues and questions using elements of group discussion, coaching, learner back-up, teacher back-up, consulting materials, teacher solution and post-instructional discussion. Teacher back-up is a contribution offered by a physics teacher to a learner who is stuck-up or confused in the course of learning a task or concept say, mentioning and associating factors of classifying waves with types of waves. Teacher solution is an answer or explanation offered by a physics teacher to enable a learner handle a problem situation such as associating each factor with types of waves. Post-instructional discussion is a conversation engaged between a physics teacher and the learners after the formal group or whole-class interaction. It is engaged to further shed explanation on a task or concept not well understood by them. In further associating some factors of classifying waves with types of waves, to mention factors of classifying waves and associate them with waves types.

The fourth pattern, "wrap up" concludes a lesson by providing summary, review, revision, assignment, homework on graded problems and reference to next day's work. Teacher encourages students to use minimum and reflective wrap up approaches. In either case, students mention key concepts learnt and summarize them at the end of the lesson (minimum wrap up) or at the end of the session (reflective wrap up) using observed experience of motion of breezy tree limb and imagined motion of object along water current in a river tossed by waves.

The fifth pattern, "Do you remember?" is based on the fact that if students have cause to proceed after a break for an hour, a day, weekend or holiday, it is likely that regression might set in. There are strategies that can be deployed by the teacher to cause the students to recoup or remember things learnt days after the break in order to refresh their memories to start a fresh lesson in a new day. The strategic elements involved in this pattern include vocabulary exercises by review. Here, students are encouraged to mention key points learnt in the class. These key points are written out on the chalkboard. Each student was asked to explain any one in his or her own words. These elements uncommonly used by physics teachers in classroom presentation, portray the pattern of running a course as a novel and unique approach to bringing about revolutionary classroom experience characteristic of meaningful learning.

Each of these five patterns is characterized by the four sections or categories including: problem (formulated as a question); forces (considerations or pull and push) that bring about solution; solution (answer to the problem) and discussion (examples and drawbacks). These sections were used in preparing the instructional packages employed for teaching the experimental group alongside the teaching-learning activities (TLAs).

Similarly, a comparison of the features of talk and chalk method which was used on the control group are four elements namely introduction, explanation/writing, questioning and summary [27-30].

a. Introduction: This is the first presentation phase of commencing the lesson on "factors of classifying waves by telling or talking and writing on white board. The talking and writing respectively carry the descriptions of "talk and chalk".

b. Explanation: This is the second presentation phase of teacher drawing students' attention to motion of breezy tree limb and motion of object along water currents in a river. Teacher lists factors of classifying waves to include: media of propagation, energy transfer, direction of displacement, direction of propagation and periodicity. Teacher explains each of these factors and the types of waves (longitudinal, transverse, travelling, standing, plane and spherical waves) associated with each factor. 
c. Questioning: This is the third presentation phase of talk-chalk method. Teacher asks students to mention any five factors of classifying waves into its types. Students ask teacher to further explain types of waves and the factors associated with each using the experience of motion of leaves and branches of breezy tree limb and imagined motion of object flowing along water currents in a river tossed by waves.

d. Summary: Teacher concludes the lesson by summarizing on: 1) Mentioning five factors considered in classifying types of waves; 2) Listing and explaining types of waves with associated factors of each type using the observed experience of moving leaves and branches of a breezy tree limb and imagined motion of objects along water current in a river tossed by waves; 3) Making reference to further "types of waves" during next class.

These elements were also used in preparing the instructional packages for the control group alongside the teaching-learning activities (TLAs). The import of this work is to again show whether the perceived low achievement of female students in male-dominated physics classrooms can be improved using the pedagogical pattern of running a course.

In proposing a solution to the problem above, this work identifies a research-based evidence of low achievement of secondary school students in physics, and that this low achievement is suspected to result from their largely poor performance in waves-related items in public examinations. The authors observed that this issue of poor students' performance in physics might be traced to physics teachers' overuse of talk and chalk method considered to be antithetic to the teaching and learning of physics and theme of waves because of its inherent lack of the potentiality for transfer of knowledge design processes of experiencing, conceptualizing, analyzing and applying [31], and scientific attitudes to both the teachers and the learners $[32,33]$. Because of this lack of transferability, the authors suggest an instructional intervention through engagement of active techniques in which a cooperative and collaborative interactive approach [34] found in pedagogical pattern of running a course could be investigated. This investigation is directed at determining whether or not the two teaching methods of pedagogical pattern of running a course and talk and chalk approach foster higher students' achievement in waves. Culturally, gender stereotypical stances arising from prejudices against women and the girl-children are well known, especially in role expectations and career opportunities [35].

This study therefore intends to also show whether the effects of talk and chalk approach on senior secondary school female students' achievement in physics can be reversed by noting whether boys or girls achieve higher when taught with pedagogical pattern of running a course. The study further determined whether or not there is significant interaction effect of the two methods and gender on students' achievement in waves.

\section{RESEARCH METHOD}

The study adopted the quasi-experimental non-randomized pretest-posttest control group design. Two study groups were used. The experimental group, taught waves with the pedagogical pattern of running a course, and the other a control group taught waves with talk and chalk method. Both groups were taught at intact classes and so normal and routine school activities were not disrupted. The area of the study is Cross River State and the study was conducted in Calabar Education Zone of the State, Nigeria. The population of the study was 4,320 students and this consisted of all the senior secondary school two (SSSII) physics students in public senior secondary schools in Calabar Education Zone. There were 83 senior secondary schools offered physics up to SSII in the Zone. Out of these were 30 co-educational schools from which six schools were drawn out for the study by use of simple random sampling technique of hat and draw. There were 216 students in the six intact classes of the six schools constituted the study sample. There were three intact classes for experimental group and the other three for control group. The sample distribution comprised 128 students (75 males and 53 females) for the experimental group and 88 students (43 males and 45 females) for the control group.

The instrument used for the study was a 50-item researcher-made test called Physics Achievement Test (PAT). It was a multiple-choice objective test with each item made of the stem, five options, four distractors and one key. The items reflected topics in waves namely: classification of waves, longitudinal waves, transverse waves, standing waves and progressive wave's equations as contained in the senior secondary school II physics curriculum. The instrument was face-validated by three experts, one physics education specialist and two test and measurement experts. These specialist and experts checked the correctness of the answers, the attractiveness of the distractors and clarity and language level of the items. Also, the content validity of the instrument was ascertained using the test-blue print of the test. Applying the Chi square test of goodness of fit to determine the content validity, it was certified that the distribution of the test items in PAT did not deviate significantly from the specification of the blue-print in which case $X_{\text {crit }}^{2}$ (31.41) $>X_{\text {cal }}^{2}(6.05)$. The difficulty index was found within the range $0.25 \leq \mathbf{P} \leq 0.62$ while the discrimination 
index was found within the range $0.25 \leq \mathbf{D} \leq 0.66$. The internal consistency of the test items was found by determining the reliability of PAT using Kuder-Richardson-20 estimated to be 0.86 . The coefficient of stability of PAT because of the use of pretest and posttest measures were determined using Pearson - product moment correlation statistics for test-retest reliability index obtained at 0.89 .

In the experimental procedure two sets of instructional packages were prepared for the study, one set for pedagogical pattern of running a course approach and the other for talk and chalk (conventional) method respectively used on the treatment and control groups. Six physics classroom teachers, one from each school of study was used as research assistant after engagement in training session for control of extraneous variables such as subject interaction, teacher variable, test wiseness, inter-group variable and instructional situation variable. For data collection, the researcher wrote to each principal of the schools of study seeking permission to use their school resources for the purpose of the research. The instrument, PAT, at the onset was administered as pretest to students in all the six schools. After the pretest was the experiment. The treatment lasted for six weeks. At the end of the experiment, a posttest was administered on the sixth week to all the subjects. The scores and results of the pretest and posttest were recorded and kept separately for use in data analysis.

\section{RESULTS AND DISCUSSION}

3.1. Research question 1: What is the effect of pedagogical pattern of running a course on senior secondary school students' achievement in waves?

Table 1 shows that the mean achievement score of secondary school students taught waves with the pedagogical pattern of running a course strategy $(\bar{x}=59.52)$ and $(\mathrm{SD}=8.56)$ is greater than that of those taught using talk and chalk method $(\bar{x}=34.39$ and $(\mathrm{SD}=6.30)$. This means that the pedagogical pattern of running a course is superior to the talk and chalk method in enhancing students' achievement in waves.

Table 1. Adjusted mean results based on teaching methods

\begin{tabular}{cccc}
\hline \multirow{2}{*}{ Method } & \multicolumn{3}{c}{ Variable } \\
& Adj. $\bar{x}$ & SD & $\mathrm{N}$ \\
\hline Running a course strategy & 59.52 & 8.56 & 128 \\
Talk and chalk method & 34.39 & 6.30 & 88 \\
\hline
\end{tabular}

\subsection{Research question 2: What is the effect of pedagogical method of running a course on secondary} school male and female students' achievement in waves?

Table 2 shows that the mean achievement score of secondary school female students $(\bar{x}=63.01$ and $\mathrm{SD}=6.41$ ) taught waves with pedagogical pattern of running a course strategy is greater than that of male students $(\bar{x}=56.96$ and $\mathrm{SD}=9.05)$ taught using the same strategy.

Table 2. Adjusted mean results based on gender

\begin{tabular}{cccc}
\hline Gender groups & Mean $\bar{x}$ & SD & $\mathrm{N}$ \\
\hline Male & 56.96 & 9.05 & 74 \\
Female & 63.01 & 6.41 & 54 \\
\hline
\end{tabular}

3.3. Research question 3: What is the interaction effect of teaching methods and gender on secondary school students' achievement in waves?

From Table 3, there is an indication that for the two levels of gender, the pedagogical pattern of running a course strategy is superior to the conventional method. This is to say that there is no interaction of teaching methods and gender on secondary school students' achievement in waves.

Table 3. Mean interaction effect of teaching methods and gender on secondary school students' achievement

\begin{tabular}{ccc}
\multicolumn{3}{c}{ in waves } \\
\hline \multirow{2}{*}{ Method } & Male $\bar{x}$ & Female $\bar{x}$ \\
& 56.96 & 63.02 \\
Running a course strategy & 32.67 & 36.86 \\
Talk and chalk method &
\end{tabular}


3.4. Hypothesis one: There is no significant difference in the mean achievement of secondary school students' taught waves with pedagogical pattern of running a course and those taught using talk and chalk method

The analysis and interpretation of data in Table 4 cover the testing of hypotheses one and three. From Table 4, the methods main effect is significant at 0.00. It means that the null hypotheses one is rejected. For the alternative, stating that there is a significant difference in the mean achievement of secondary school students' taught waves with pedagogical pattern of running a course and those taught using talk and chalk method.

Table 4. ANCOVA results based on gender

\begin{tabular}{cccccc}
\hline Source of variation & Sum of squares & df & Mean square & F & Sig. of F \\
\hline Covariate & 1068.22 & 1 & 1068.22 & 18.54 & 0.00 \\
Pretest & 1068.22 & 1 & 1068.22 & 18.54 & 0.00 \\
Main effects & 1022.15 & 1 & 1022.15 & 17.74 & 0.00 \\
Gender & 1022.15 & 1 & 1022.15 & 17.74 & 0.00 \\
Explained & 2090.38 & 2 & 1045.18 & 18.14 & 0.00 \\
Residual & 7144.50 & 124 & 57.62 & & \\
Total & 9234.88 & 126 & 73.29 & & \\
\hline
\end{tabular}

3.5. Hypothesis two: There is no significant difference in the mean achievement of male and female secondary school students taught waves with the pedagogical pattern of running a course

Table 5 reveals that gender is significant at 0.0 meaning that the null hypothesis is rejected for the alternative. Therefore, there is a significant difference in the mean achievement of male and female secondary school students taught waves with the pedagogical pattern of running a course.

Table 5. ANCOVA results based on interaction effect of teaching methods and gender

\begin{tabular}{cccccc}
\hline Source of variation & Sum of squares & df & Mean square & F & Sig. of $F$ \\
\hline Covariate & 2183.44 & 1 & 2183.44 & 43.93 & 0.00 \\
Pretest & 2183.44 & 1 & 2183.44 & 43.93 & 0.00 \\
Main effects & 32925.79 & 2 & 16462.90 & 331.24 & 0.00 \\
Gender & 1188.46 & 1 & 31737.32 & 638.58 & 0.00 \\
2-way interaction & 94.22 & 1 & 94.22 & 1.90 & 0.17 \\
Method gender & 94.22 & 1 & 94.22 & 1.90 & 0.17 \\
Explained & 35203.46 & 4 & 8800.86 & 177.08 & 0.00 \\
Residual & 10487.88 & 211 & 49.70 & & \\
Total & 45691.33 & 215 & 212.52 & & \\
\hline
\end{tabular}

3.6. Hypothesis three: There is no significant interaction between teaching methods and gender on secondary school students' achievement in waves

Table 4 shows the 2-way interaction effect of teaching methods and gender. This interaction effect is not significant at 0.17 , meaning that the null hypothesis three is retained. Thus, there is no significant interaction effect of teaching methods and gender on secondary school students' achievement in waves. This further implies that the effect of teaching methods at the levels of pedagogical pattern of running a course and talk and chalk method is the same at all levels of gender on secondary school students' achievement in waves.

Results in Table 1 showed that the pedagogical pattern of running a course strategy is superior to the conventional method in fostering secondary school students' achievement in waves. The students in the treatment group achieved higher mean score $(\bar{x}=59.52)$ than those in the control group $(\bar{x}=34.39)$. Also, students in the treatment group obtained higher mean achievement score revealed in method main effect $(\mathrm{F}=638.58)$. This implied that the pedagogical pattern of running a course affected students more positively than the talk-chalk method. This result agrees with the studies of Offor in Nwankwo [12] and Odo [34] that there is urgent need for a paradigm shift from the conventional way physics is being taught in the classroom, to a more creative pattern that is learners' friendly.

In addition, on hypothesis two that says that there is no significant difference in the mean achievement of male and female secondary school students taught waves with pedagogical pattern of running a course, the findings showed that there was a significant difference in the achievement of male and female students taught using pedagogical pattern of running a course method. In Table 2, male students obtained less mean achievement score $(\bar{x}=56.96)$ than female students' mean achievement score $(\bar{x}=63.01)$. Similarly, on the gender and method main effects $(\mathrm{F}=17.74)$ at 0.05 level of significance. 
Table 5 shows that the pedagogical pattern of running a course discriminated between male and female students' achievement in waves. This finding was supported by Nigeria's statistics of physics students' performance in May/June (2008-2016) West African Secondary School Certificate Examination results of male and female students. The results were appraised and it revealed superior performance of female students to male students in physics for nine years consistently. This evidence was shown in higher mean percentage credit pass (1-6) for female students $(62.61 \%)$, than male students $(56.53 \%)$ [5]. The use of contextualized teaching-learning practice environment in which the pedagogical pattern of running a course thrives seemed to be more female-friendly. Here, boys and girls participated in waves learning tasks through co-operative and collaborative learning groups in which roles are well defined and related so that everyone has equal chance to exhibit competence and be more motivated to participate [36]. Such participation brought about the phenomenal turning point in achievement in favor of female students. Despite this superior achievement of running a course over talk and chalk, it is held that it might be misleading to conclude that latter pedagogies such as running a course supersede former ones such as talk and chalk. The more thing changes, the more they stay the same. More so, the issue of gender-related achievement in science subjects and mathematics is not conclusive because of seeming conflicting research report as replete in literature [37].

For research question 3 and 4, the hypothesis three stating that there is no interaction effect of teaching methods and gender on secondary school students' achievement in waves, the results of finding showed that there is no interaction of teaching methods and gender on secondary school students' achievement in waves. Table 3 showed that the mean interaction effect of pedagogical pattern of running a course on male $(\bar{x}=56.96)$ and female $(\bar{x}=63.02)$ students' achievement in waves is increasingly higher than that of talk and chalk on male $(\bar{x}=32.67)$ and female $(\bar{x}=36.86)$ students' achievement in waves. Table 4 shows the 2-way interaction of teaching methods and gender $(\mathrm{F}=1.9)$ at 0.17 significant level, implies that there is no interaction of teaching methods and gender on secondary school students' achievement in waves. This means that the pedagogical pattern of running a course strategy can be used to teach both male and female students' in the same class to produce the same achievement in waves. This finding seems to agree with that of Nervile [11] and Odo [34] who investigated about changing pedagogical processes and found that teacher made significant progress in male and female students' achievement thereby resulting in classroom revolutionary experience.

\section{CONCLUSION}

The study concluded that students' classroom revolutionary experience is acquired because the pedagogical pattern of running a course is superior to the conventional talk and chalk method in fostering students' achievement in waves through creating a context in which physics learning can happen. The pattern of running a course does not discriminate between male and female students hence no interaction effect of teaching methods and gender on secondary school students' achievement in waves.

The study recommended that pedagogical pattern of running a course strategy should be adopted in the Nigerian secondary school education system and for training of teachers. Government at all levels should collaborate with all stakeholder in education to garner every resource (both material and personnel) to organize in-service training in the form of conferences, workshops and seminars for teachers in order to discuss how this creative and innovative method can be made practicable in the classroom and researchers on pedagogical pattern of running a course strategy should ascertain its intensiveness in terms of cost and materials so as to be guided in the review of secondary school physics curriculum.

\section{REFERENCES}

[1] Ivowi, U. M. O., "Achievement level in understanding physics concepts in secondary schools," Journal of Research in Curriculum, vol. 1, no. 2, pp. 23-34, 1993.

[2] Nigerian Educational Research and Development Council (NERDC), Senior secondary school physics curriculum. Abuja: Federal Ministry of Education, 2009.

[3] Idiege, K. J., Elenwoke, U. E., and Okore, S. E., "Science laboratory: Resource tools for quality delivery of secondary school chemistry concept for technology and economic development in Nigeria," Multidisciplinary Journal of Research and Development Perspective, vol. 6, no. 2, pp. 125-139, 2017.

[4] Neji, H. A., Ntibi, J. E. and Agube, C. C., "Communicating chemistry and physics through hands-on activities: A scalable innovative approach to promote students' performance and entrepreneurial skills," Multidisciplinary Journal of Research and Development Perspective, vol. 6, no. 2, pp. 32-39, 2017.

[5] Nkwo, N. I., "Effects of pedagogical pattern of running a course on secondary school students' achievement in waves," Unpublished Ph.D Thesis, Ebonyi State University, Abakaliki, Nigeria, 2020.

[6] Uche, S. C., "Assessment of students' learning in science," Akamkpa Journal of Science and Mathematics Education, vol. 1, no. 1, pp. 31-44, 1997. 
[7] West African Examinations Council (WAEC), "Chief Examiners' report on physics paper 2 May/June (20112014)," Sidmach Technologies (Nigeria) Ltd, 2012-2015.

[8] Okebukola, P. A., Beyond the stereotypes to new trajectories in science teaching. Text of special lecture presented at the 43rd Science Teachers Association of Nigeria (STAN) and Commonwealth Association of Science, Technology and Mathematics Educators (CASTME), August, 22, 2002.

[9] Nkwo, N. I., "Influence of non-scientific belief misconceptions on senior secondary school students' achievement in physics," Journal of the Science Teachers Association of Nigeria (JSTAN), vol. 54, no. 1, pp. 37- 54, 2019.

[10] Eckstein, J., "Learning to teach and learning to learn: Running a course," Proceedings of Euro PLoP 2000, UKV Konstanz, 2001.

[11] Nervile, M., Teaching multimodal literacy using the learning by design approach to pedagogy. Melbourne University Press and Common Ground, 2008.

[12] Nwankwo, A. O., History of education in Nigeria. Enugu: Tons and Tons, 2014

[13] Nneji, S. O., "Effect of dart game on secondary school students' interest in algebra," Journal of the Science Teachers Association of Nigeria (JSTAN), vol. 54, no. 1, pp. 1-9, 2019.

[14] Senturk, S. and Duran, V., "Lifelong learning tendencies in adult education," International Journal of Evaluation and Research in Education (IJERE), vol. 9, no. 1, pp. 1-9, 2020.

[15] Ekwueme, C. O., Ekon, E. E., and Ezenwa-Nebife, D. C., "Education for sustainability through academic freedom," Global J. Educ. Res., vol. 15, pp. 23-30, 2016.

[16] Uwaezuoke, F. O. and Charles-Ogan, G., "Teaching mathematics creatively in the junior secondary classes," Global J. Educ. Res., vol. 15, pp. 1-6, 2016.

[17] Bidwell, C. E., "The social psychology of teaching," In Robert M.W. Trasvers, Ed. Second Handbook Research in Teaching. Chicago: Rand McNally College, 1973.

[18] Mgbekem, M. A., et al., "Teaching practice experiences of nursing students: A comparison between direct entry and generic students of Departmentof Nursing Science, University of Calabar, Calabar," Global J. Educ. Res., vol. 15, pp. 7-22, 2016.

[19] Nkwo, N. I., "Re-cultivating scientific attitudes in secondary school physics students for academic integrity," Paper Presented at the Maiden National Conference of Faculty of Education, Cross River University of Technology, Calabar Cross River State, Nigeria, 2019.

[20] Pask, G., Conversational theory: Applications in education and epistemology. Amsterdam: Elsevier, 1976.

[21] Sule, M. A., "Supervision of students' learning activities in universities and the development of the total person in Cross River State," Multi-disciplinary Journal of Research and Perspective, vol. 6, no. 2, pp. 140-149, 2017.

[22] Nkwo, N. I., "Needs requirements for implementation of physics in technology curriculum on senior secondary school students' achievement in Nigeria," Brit. Int. J. Educ. and Soc. Sci., vol. 6, no. 6, pp. 1-11,2019.

[23] Nkwo, N. I. and Nsungo, A., "Recent trend in data-handling techniques for senior secondary school students' physics practical in Nigeria," Multi-disciplinary J. Res. and Perspective, vol. 6, no. 2, pp. 100-115, 2017.

[24] Reuping, A., "Project documentation management," Proceedings of Euro PLoP, Agile documentation: A pattern guide to producing lightweight documents for software projects. Chichester: John Willey \& Sons Ltd, 2003.

[25] Laurillard, D. and Ljubojevic, D., Evaluating leaning designs through the formal representation of pedagogical patterns. London: London Knowledge Lab. U.K, 2009.

[26] Wellington, J. J., "What's supposed to happen, Sir? Some problems with discovery learning," Journal of the Science Teachers Association of Nigeria, vol. 2, no. 1, pp. 168-180, 1982.

[27] Emina, F.I., Aigbomian, D. O. and Inomiesa, E. A., "Subject method in natural sciences," A handbook for the teaching of sciences. Agbor: Central Books Limited, 1993.

[28] Ekawu, D. O., Egbe, C.A. and Egim, S., "History teaching method," in Oru Ebam and M. J. Ada, Eds. Instructional Methods. Calabar: Centaur Publishers, 1998.

[29] Ingwu, E. O., Ogar, M. N. and Ada, M. J., "General teaching methods," in Oru Ebam and M. J. Ada, Eds. Instructional Methods. Calabar: Centaur Publishers, 1998.

[30] Adeoye, F. M., et al., Edu.244: Subject methods II physics for undergraduates. National Open University of Nigeria (NOUN), Lagos: Moks Services International Ltd, 2006.

[31] Nkwo, N. I., "Scientific attributes of physics education for transformation, reformation and moral development in a depressed economy," Int. J. Recent Innov. in Appl. Phys. and Appl., vol. 1, no. 1, pp. 1-14, 2018.

[32] Effiong, U. U., Nkwo, N. I., and Udo, N. N., "Test types, students' achievement in senior secondary school physics, eradication of poverty and hunger in Nigeria," IOSR-JRME, vol. 4, no. 1, ver. iii, pp. 1-5, 2014.

[33] Kalantzis, M. and Cope B., "The teacher as a designer: Pedagogy in the new media age," E-learning and Digital Media, vol. 7, no. 3, pp. 200-222, 2010.

[34] Odo, E. E., "Effects of jigsaw instructional strategy on secondary school students' achievement in chemistry," Unpublished Ph.D Thesis, Ebonyi State University, Abakaliki, Ebonyi State, Nigeria, 2019.

[35] Anugwo, M. N., "Evaluation instrument used by primary and secondary school teachers: Implication for the reforms and transformation of girl-child education," International Journal of Forum for African Women Educationalists in Nigeria, vol. 2, no. 1, 2010.

[36] Baker, D. R., A Female-friendly science classroom. In Research matters to the science teacher. A publication of the National Association of Research in Science Teaching. New York: Macmillan Research Matters IndexNARST,1996.

[37] Sukolatambaya, I., "The impact of prior exposure to biology terminologies on academic performance of secondary school students in Dutsin-Ma Metropolis," J. Sci. Teacher Assoc. of Nigeria, vol. 54, no. 1, pp. 11-18, 2019. 